\title{
Making it personal: a biography of connections
}

Previously published at www.cmaj.ca

\section{Brooklyn Beginnings: A Geriatrician's Odyssey}

Michael Gordon

iUniverse, Inc.; 2009.

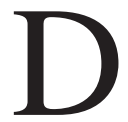
r. Michael Gordon is perhaps better known as the first physician to hold a certificate from the Royal College of Physicians and Surgeons in geriatric medicine, or as a medical ethicist with an interest in elderly and end-of-life care, or as the coauthor of the book Parenting Your Parents.

This autobiography merely glances over these accomplishments. Instead, it presents a compilation of thematically categorized stories that may have seemed insignificant when they occurred, but later, with the clarity of hindsight, contributed to his beshert (the Yiddish and Hebrew term for destiny).

He recounts his love for music (entrenched from his Lithuanian-Jewish grandmother with whom he shared a room during childhood), his Scottish medical education, nomadic travels through Europe, adventures as a draft dodger during the Vietnam War, service as a physician in the Israeli Air Force, experience of Israel's Six-Day War in Tunisia and ethical conundrums in caring for aging Holocaust survivors. His life journey is full of personal cont nections, some interesting and others seemingly ordinary.

Perhaps the deliberate focus on these sorts of events was the author's way of illustrating that the accumulation of personal relationships is what defines us and lends us to our accom-

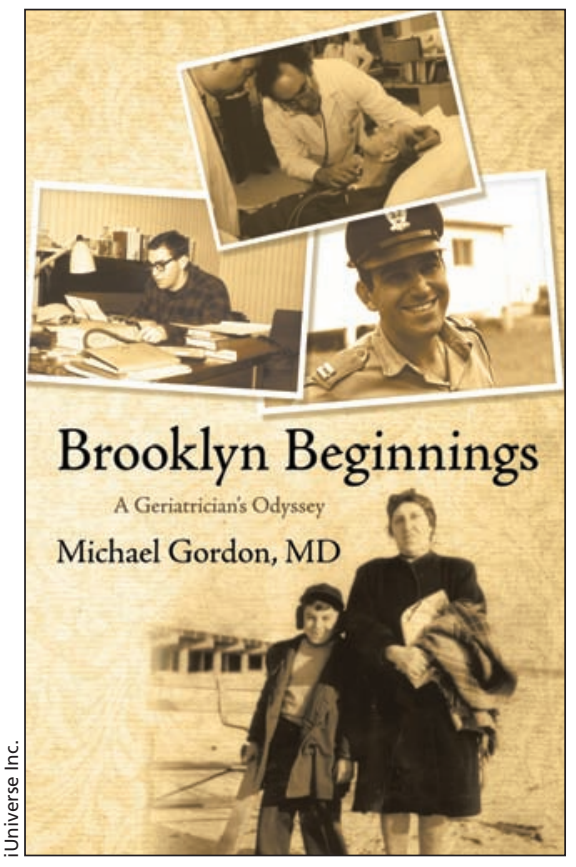

plishments. However, the autobiography may have benefited from a judicious editing of some details of his sexual escapades and the reader who is looking for more details on his milestones as an ethicist and geriatrician will be disappointed.

The book begins lightly, often with interjections of humour, such as when he tries to master Hebrew:

"The word for lollipop is succharia al makel. What, in fact, you have been saying is "diabetes on a stick" since the word sukkerit is the sugar illness you know ... diabetes."

His anecdotes are not all funny and later develop a reflective slant. For example, when he tries to explain to students how all these life events were simply a prologue to a satisfying career in geriatrics:

"... the field of geriatrics is neither depressing nor futile. In contrast, it is full of medical challenges and the great satisfaction of dealing with individuals who have had long, varied, and often very fascinating lives and experiences."

He reminds the reader of the humility of our own humanity; that, despite being a physician (and a geriatrician at that), even he was not immune to the challenges of an aging parent or the sadness in caring for a dying parent. His honesty is refreshing.

The ease with which he builds from candid and emotional dialogue toward philosophical reflection makes for an easy read. While an easy read, it is ironic that the reader may feel distant from the author considering he seems to be a man who savours everyday personal interactions. Approach the book more like a conversation with a stranger at a café where the direction of the interaction may not seem to have an objective.

For a man with so many anecdotes to tell, it begs the question of whether this narrative of life stories is a premature autobiography or simply beshert that will inspire another chapter of his life. Gordon writes that his motive for writing the book was so that it would be "Something to refer to should they [his children] want to know some of the details of my life when I may not be in a position to tell them personally." His book reminds us, whether or not a physician, of the importance of making personal connections with those around us.

Camilla L. Wong MD MHSc

Division of Geriatrics

University of Toronto

Toronto, Ont. 